\title{
Pengujian Kemampuan Adsorpsi Dari Adsorber Karbon Aktif Dan Alumina Aktif Yang Digunakan Untuk Mesin Pendingin Tenaga Surya
}

\author{
Tri Arfandi ${ }^{1}$, Tulus B Sitorus ${ }^{2}$, Himsar Ambarita ${ }^{3}$, Farel H. Napitupulu ${ }^{4}$, Dian M. Nasution ${ }^{5}$ \\ ${ }^{1,2}$ Departemen Teknik Mesin, Fakultas Teknik, Universitas Sumatera Utara \\ Email:Tri.arfandi@yahoo.co.id
}

\begin{abstract}
ABSTRAK
Akhir-akhir ini mesin pendingin siklus adsorpsi semakin banyak diteliti oleh para ahli karena disamping ekonomis juga ramah lingkungan dan menggunakan energi terbarukan yaitu energi surya. Agar proses adsorpsi dan desorpsi mesin pendingin adsorpsi dapat berjalan dengan baik perlu diketahui jumlah perbandingan yang ideal antara adsorben dengan refrigeran yang digunakan. Tujuan disini untuk mencari perbandingan antara absorben karbon aktif dan alumina aktif menggunakan mimis maupun tidak menggunakan mimis. Data tersebut dapat dicari menggunakan alat penguji kapasitas adsorpsi. Alat penguji kapasitas adsorpsi yang digunakan dilengkapi dengan lampu halogen $1000 \mathrm{~W}$ sebagai sumber panas. Adsorber pada alat penguji ini terbuat dari bahan stainless steel yang bertujuan agar tahan terhadap korosi akibat dari variasi refrigeran yang digunakan. Campuran karbon aktif dan alumina aktif yang digunakan sebagai adsorben sebanyak $1 \mathrm{~kg}$. Sedangkan variasi refrigeran yang digunakan yaitu metanol. Hasil penelitian kapasitas metanol yang dapat diadsorpsi dan didesorpsi oleh adsorben karbon aktif dan alumina aktif mengunakan mimis adalah sebanyak $350 \mathrm{~mL}$. Sedangkan kapasitas metanol yang dapat diadsorpsi dan didesorpsi oleh adsorben karbon aktif dan alumina aktif tidak menggunakan mimis adalah sebanyak $250 \mathrm{~mL}$.
\end{abstract}

Kata kunci: Adsorpsi, desorpsi, adsorber, karbon aktif, alumia aktif, refrigeran.

\section{PENDAHULUAN}

Proses pendinginan merupakan suatu usaha untuk menurunkan suhu pada ruangan ataupun pada suatu material, dengan kata lain mendapatkan kondisi yang diinginkan oleh produk atau material, dalam hal ini temperatur yang rendah agar produk atau material dapat disimpan dalam waktu yang relatif lama, baik untuk konsumsi, produksi, maupun perdagangan. Penyimpanan dan transportasi bahan pangan, proses pengolahan makanan dan minuman, pembuatan es (ice making) merupakan beberapa contoh kegiatan yang memerlukan proses pendinginan dan pembekuan. Proses pendinginan merupakan proses pengambilan kalor / panas suatu ruang atau benda untuk menurunkan suhunya dengan jalan memindahkan kalor yang terkandung dalam ruangan atau benda tersebut. Sehingga proses pendinginan merupakan rangkaian proses pindah panas. Proses pindah panas dapat terjadi secara konveksi, konduksi maupun radiasi[1].

Salah satu opsi yang cukup potensial memanfaatan energi surya termal adalah untuk menggerakkan siklus adsorpsi untuk daerah-daerah yang tidak mempunyai aliran listrik. Sementara banyak desa-desa di Indonesia yang sangat membutuhkan mesin pendingin (refrigerasi) untuk membantu aktivitas ekonomi. Misalnya untuk pengawetan dan pembuatan makanan, atau untuk penyimpanan vaksin dan lain-lain. Oleh karena itu mesin pendingin yang dapat digerakkan energi matahari dan tidak memerlukan listrik sangat dibutuhkan terutama untuk daerah-daerah pedesaan di Indonesia.

\section{TINJAUAN PUSTAKA Siklus Adsorpsi}

Adsorpsi adalah suatu proses yang terjadi ketika suatu fluida (cairan maupun gas) terikat pada suatu padatan (zat penyerap, adsorben) dan akhirnya membentuk suatu lapisan tipis atau film (zat terserap: adsorbat) pada permukaannya. 
Berbeda dengan absorpsi yang merupakan penyerapan fluida oleh fluida lainnya dengan membentuk suatu larutan.

Adsorpsi dibedakan menjadi dua jenis, yaitu adsorpsi fisika yang disebabkan oleh gaya Van Der dan secara kimia (terjadi reaksi antara zat yang diserap dengan adsorben).

Apabila daya tarik menarik antara zat terlarut dengan adsorben besar maka zat yang terlarut akan diadsorpsi pada permukaan adsorben. Inilah yang disebut dengan gaya Van Der Waals. Pada proses ini gaya yang menahan molekul fluida pada permukaan solid relatif lemah, dan besarnya sama dengan gaya kohesi molekul pada fase cair (gaya Van Der Waals) mempunyai derajat yang sama dengan panas kondensasi dari gas menjadi cair. Keseimbangan antara permukaan solid dengan molekul fluida biasanya cepat tercapai dan bersifat reversibel[2].

\section{Adsorben}

a.Karbon Aktif

Karbon aktif merupakan suatu padatan berpori yang mengandung 85-95\% karbon, dihasilkan dari bahan-bahan yang mengandung karbon dengan pemanasan pada suhu tinggi. Ketika pemanasan berlangsung diusahakan agar tidak terjadi kebocoran udara di dalam ruangan pemanasan sehingga bahan yang mengandung karbon tersebut hanya terkarbonisasi dan tidak teroksidasi. Karbon aktif selain digunakan sebagai bahan bakar, juga dapat digunakan sebagai adsorben (penyerap). Daya serap ditentukan oleh luas permukaan partikel dan kemampuan ini dapat menjadi lebih tinggi jika terhadap karbon aktif tersebut dilakukan aktivasi dengan aktif faktor bahan-bahan kimia ataupun dengan pemanasan pada temperatur tinggi[3].

b.Alumina Aktif

Alumina aktif dibuat dari aluminium hidroksida dengan dehydroxylating dengan cara yang menghasilkan bahan yang sangat berpori, bahan ini dapat memiliki luas permukaan signifikan lebih dari 200 meter persegi / g. Senyawa ini digunakan sebagai pengering dan sebagai filter fluoride, arsenik dan selenium dalam air minum. Alumina aktif terbuat dari aluminium oksida (alumina, Al2O3), substansi kimia yang sama seperti safir dan ruby. Ini memiliki luas permukaan yang sangat tinggi untuk rasio berat, karena banyak "terowongan seperti" pori-pori[4].

\section{Metanol}

Metanol juga dikenal sebagai metil alkohol, wood alcohol atau spiritus. Metanol merupakan bentuk alkohol paling sederhana. Pada keadaan atmosfer, metanol berbentuk cairan yang ringan, mudah menguap, tidak berwarna, mudah terbakar dan beracun dengan bau yang khas (berbau lebih ringan dari pada etanol). Metanol digunakan sebagai bahan pendingin anti beku, pelarut, bahan bakar dan sebagai bahan aditif bagi etanol industri[5].

\section{Keamanan Refrigeran}

Refrigeran dirancang untuk digunakan pada ruangan tertutup atau tidak bercampur dengan udara luar. Jika ada kebocoran karena sesuatu hal yang tidak diinginkan, maka refrigeran ini akan keluar sistem dan bisa saja terhirup oleh manusia. Untuk menghindari hal-hal yang tidak diinginkan maka refrigeran harus dikategorikan aman atau tidak aman. Ada dua faktor yang digunakan untuk mengklasifikasikan refrigeran berdasarkan keamanan, yaitu bersifat racun dan mudah terbakar. 


\section{Kalor (Q)} suhu[6].

Kalor adalah salah satu bentuk energi yang dapat mengakibatkan perubahan

\section{a.Kalor Laten}

Energi yang diperlukan disebut kalor transformasi. Kalor yang diperlukan untuk merubah fasa dari bahan bermassa m adalah

$$
Q_{L}=L_{e} m
$$

Dimana :

$Q_{L}=$ Kalor laten $(\mathrm{J})$

$L e=$ Kapasitas kalor spesifik laten $(\mathrm{J} / \mathrm{kg})$

$M=$ Massa zat $(\mathrm{kg})$

b. Kalor Sensibel

kalor sensibel adalah kalor yang diberikan atau yang dilepaskan oleh suatu jenis fluida sehingga temperaturnya naik atau turun tanpa menyebabkan perubahan fasa fluida tersebut.

$Q_{s}=m C_{p} \Delta T$

Dimana:

$Q_{s} \quad=$ Kalor sensible $(J)$

$C_{p} \quad=$ Kapasitas kalor spesifik sensibel (J/kg.K)

$\Delta T \quad=$ Beda temperatur $(\mathrm{K})$

\section{Perpindahan Panas}

Mekanisme perpindahan panas yang terjadi dapat dikategorikan atas 3 jenis yaitu: konduksi, konveksi dan radiasi.

-Konduksi

Secara matematik, untuk plat datar seperti gambar di atas ini, laju perpindahan panas konduksi dirumuskan dengan persamaan:

$$
Q_{c}=k A \frac{\Delta T}{\Delta x}
$$

Atau sering dirumuskan dengan persamaan berikut ini.

Dimana:

$$
Q_{c}=k A \frac{d T}{d x}
$$

$Q_{c} \quad=$ Laju aliran energi $(\mathrm{W})$

A $\quad$ Luas penampang $\left(\mathrm{m}^{2}\right)$

$\Delta \mathrm{T}=$ Beda temperatur $(\mathrm{K})$

$\Delta x \quad=$ Panjang $(\mathrm{m})$

$\mathrm{k}=$ Daya hantar (konduktivitas) (W/m.K)

- Konveksi

Secara matematik perpindahan panas konveksi pada permukaan pelat rata dapat dirumuskan dengan persamaan berikut ini.

Dimana:

$$
Q_{h}=h A\left(T_{s}-T_{L}\right)
$$

$Q_{h} \quad=$ Laju perpindahan panas konveksi (W)

$h \quad=$ Koefisien $\operatorname{konveksi}\left(\mathrm{W} / \mathrm{m}^{2} \mathrm{~K}\right)$

$A \quad=$ Lluas penampang perpidahan panas $\left(\mathrm{m}^{2}\right)$

$T_{s} \quad=$ Temperatur permukaan

$T_{L} \quad=$ Temperatur fluida 
-Radiasi

Persamaan yang dapat digunakan untuk menghitung laju perpindahan panas radiasi antara permukaan pelat (gambar 2.10) dan lingkungannya adalah:

$$
Q_{r}=e \sigma A T^{4}
$$

Dimana

$Q_{r} \quad$ = Laju perpindahan panas radiasi $(\mathrm{W})$

$\sigma \quad=$ Konstanta Boltzman: $5,67 \times 10^{-8} \mathrm{~W} / \mathrm{m}^{2} \mathrm{~K}^{4}$

e $\quad=$ Emisivitas $(0 \leq \mathrm{e} \leq 1)$

$\mathrm{T} \quad=$ Temperatur $(\mathrm{K})$

\section{METODOLOGI PENELITIAN}

\section{Tempat dan Waktu}

Tempat penelitian adalah laboratorium Teknik Pendingin, gedung Fakultas Teknik USU. Waktu pelaksanaan penelitian \pm 5 bulan.

\section{Bahan}

Pada penelitian ini, bahan pengujian yang digunakan adalah sebagai berikut.

1. Adsorben karbon aktif dan alumina aktif

Adsorben yang digunakan pada penelitian ini adalah karbon aktif sebanyak 500 gram dan 500 gram alumina aktif. Dimana pengujian ini membedakan isinya dalam adsorben menggunakan mimis dan tidak menggunakan mimis.

2. Refrigeran

Untuk terjadinya suatu proses pendinginan diperlukan suatu bahan yang mudah dirubah bentuknya dari gas menjadi cair atau sebaliknya. Refrigeran yang digunakan pada pengujian ini adalah:

- Metanol dengan kadar kemurnian 99\% sebanyak 1 liter

\section{Alat Ukur yang Digunakan pada Pengujian Kapasitas Adsorpsi}

Alat-alat ukur yang digunakan pada pengujian kapasitas adsorpsi ini adalah Manometer Vakum, Agilent.

\section{Peralatan yang Digunakan}

Pompa Vakum, Katup, Pipa Penghubung, Selang Karet, Stainless steel ball (Mimis), Kotak Isolasi gelas ukur.

\section{Prosedur Pengujian}

Prosedur pengujian dapat diuraikan sebagai berikut ini.

1. Proses assembling/penyambungan alat penguji kapasitas adsorpsi. Komponen adsorber dengan gelas ukur dirangkai/dihubungkan dengan baik. Pada persambungan pipa dilem dengan baik dan kuat untuk menghindari kebocoran.

2. Kemudian dipasang termokopel agilent, pada adsorber (4 titik) dan pada gelas ukur (3 titik). Agilent dinyalakkan sehingga data-data temperatur pada setiap titik termokopel tersimpan otomatis.

3. Adsorber dipanaskan selama 9 jam (mulai pukul 9.00 WIB sampai dengan pukul 17.00 WIB).

4. Kemudian pada pukul $17.00 \mathrm{WIB}$ dilakukan pemvakuman dengan mengunakan pompa vakum untuk mengeluarkan gas/udara dan air/uap air yang terdapat pada adsorben karbon aktif. Setelah kondisi vakum, kemudian semua katup ditutup. 
5. Pada gelas ukur diisi refrigeran. Pengujian pertama mengunakan metanol, pengujian kedua menggunakan etanol, pengujian ketiga menggunakan amonia dan pengujian terakhir adalah refrigeran musicool. Kemudian lampu alat penguji kapasitas adsorpsi dimatikan. Data temperatur adsorber dan gelas ukur akan otomatis tersimpan pada agilent dalam bentuk excel.

6. Kemudian gelas ukur dimasukkan ke dalam kotak styrofoam dan pada styrofoam diisikan es sebanyak $5 \mathrm{~kg}$. Hal ini bertujuan untuk melihat berapa refrigeran yang dapat diserap oleh karbon aktif dengan kondisi bagian luarnya sudah menjadi es. Karena gelas ukur nantinya akan digantikan fungsinya oleh evaporator pada mesin pendingin siklus adsorpsi tenaga surya.

7. Katup antara adsorber dan gelas ukur dibuka untuk memulai proses adsorpsi (pukul 17.00 WIB sampai keesokan harinya pukul 9.00 WIB). Temperatur adsorber akan turun seiring dengan turunnya temperatur lingkungan. Pada malam hari dengan turunya temperatur adsorber, maka karbon aktif akan menyerap refrigeran sehingga refrigeran akan menguap dan naik ke adsorben karbon aktif. Tekanan adsorpsi dicatat setiap jamnya.

8. Proses desorpsi mulai pukul 9.00 WIB sampai dengan pukul 17.00 WIB dengan menyalakkan lampu pemanas alat penguji kapasitas adsorpsi (1000 W). Seiring dengan naiknya temperatur adsorber maka refrigeran akan menguap dari adsorben karbon aktif dan masuk ke gelas ukur dalam fasa cair.

\section{Alat Pengujian Percobaan}
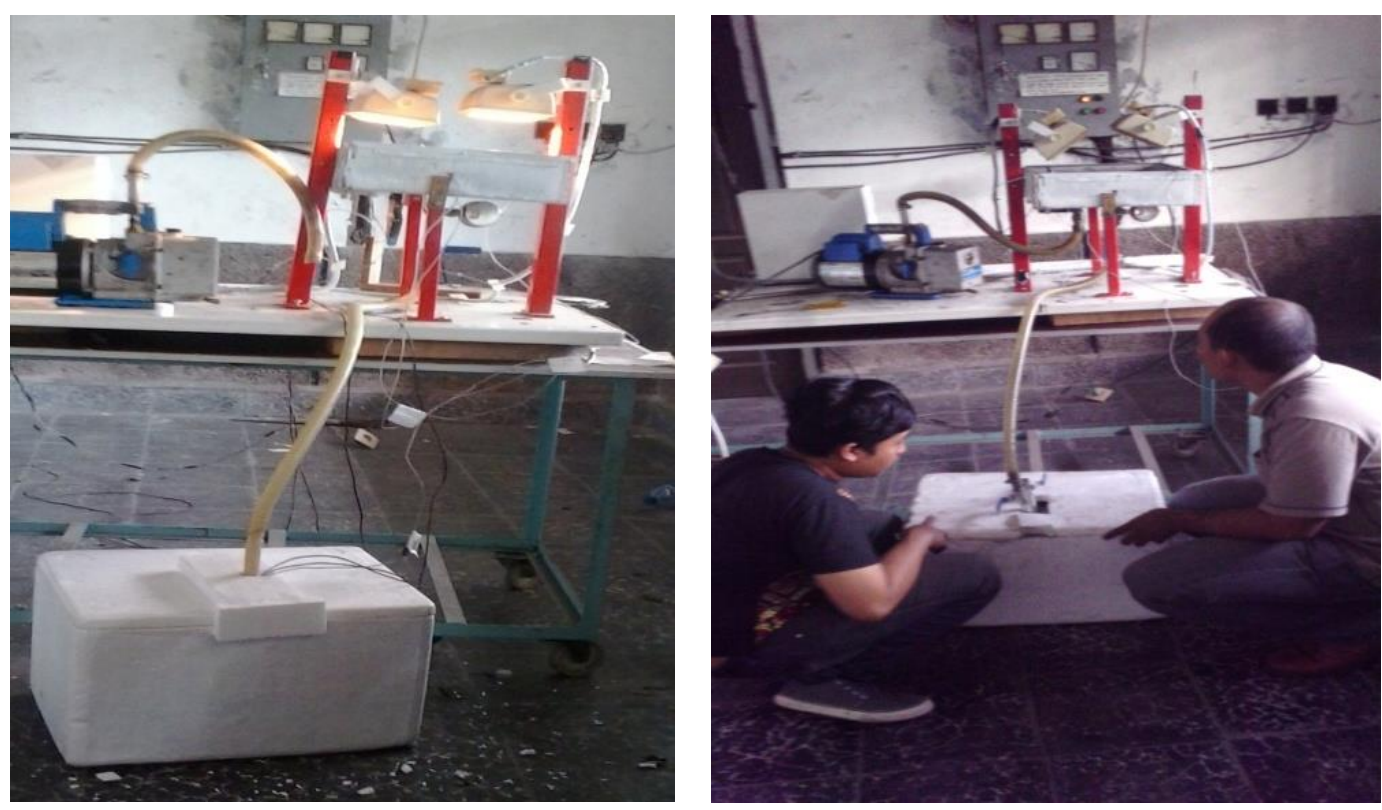

Gambar 1 : Alat Penguji Kapasitas Adsorpsi dan Desorpsi dengan gelas ukur Disolasi 


\section{ANALISA DATA}

Data yang diambil dari pengujian adalah data temperatur adsorber, data temperatur gelas ukur, kapasitas adsorpsi dari adsorben karbon aktif dan alumina aktif dengan menggunakan mimis terhadap beberapa jenis refrigeran dan juga tekanan dalam alat uji kapasitas adsorpsi.

\section{Data Pemakuman Alat Penguji Kapasitas Adsorpsi}

- Pada menggujian absorber menggunakan mimis.

Temperatur awal percobaan pada adsorber adalah $26,95^{\circ} \mathrm{C}$. Temperatur maksimum adsorber yang dapat dicapai ketika pemanasan adalah $255,68^{\circ} \mathrm{C}$ yaitu berada titik 8 thermocouple (pada pukul 14.57 WIB). Temperatur rata-rata adsorber bagian atas pada proses pemvakuman adalah $204,98^{\circ}$ C. Temperatur pada titik channel 7 (adsorber bawah) $T_{b}$ adalah $184,28^{\circ} \mathrm{C}$.

- Pada penggujian absorber tidak menggunakan mimis.

Temperatur awal percobaan pada adsorber adalah $27,01^{\circ} \mathrm{C}$. Temperatur maksimum adsorber yang dapat dicapai ketika pemanasan adalah $171,39^{\circ} \mathrm{C}$ yaitu berada titik 8 thermocouple (pada pukul 16.55 WIB). Temperatur rata-rata adsorber bagian atas pada proses pemvakuman adalah 119,40 ${ }^{\circ}$. Temperatur pada titik channel 7 (adsorber bawah) $T_{b}$ adalah $79,13^{\circ} \mathrm{C}$.

\section{Data Pengujian Adsorpsi}

Berikut ini ditampilkan tabel data-data tekanan dan temperatur rata-rata setiap jam pada proses adsorpsi metanol dengan adsorben karbon aktif dan alumina aktif dengan menggunakan mimis.

Tekanan awal pada proses adsorpsi ini adalah -0.5333 Bar. Tekanan ini diperoleh setelah dilakukan pemvakuman dengan mengunakan pompa vakum. Tekanan pada keesokan harinya menurun menjadi -0.8333 pada pukul 9.00 WIB. Penurunan tekanan ini disebabkan oleh penurunan temperatur alat uji kapasitas adsorpsi. Temperatur rata-rata terendah yang dapat dicapai pada adsorber terjadi pada pukul $05.00 \mathrm{WIB}$ yaitu $25,02^{\circ} \mathrm{C}$.

- $\quad$ Berikut ini ditampilkan tabel data-data tekanan dan temperatur rata-rata setiap jam pada proses adsorpsi methanol dengan adsorben karbon aktif dan alumina aktif tanpa menggunakan mimis.

Tekanan awal pada proses adsorpsi ini adalah -0,5333 Bar. Tekanan ini diperoleh setelah dilakukan pemvakuman dengan mengunakan pompa vakum. Tekanan pada keesokan harinya menurun menjadi $-0,7599$ Bar pada pukul 09.00. Temperatur rata-rata terendah yang dapat dicapai pada adsorber terjadi pada pukul 08.55 WIB yaitu $26,01^{\circ} \mathrm{C}$. 
Tabel 1 : Hasil Perhitungan Pegujian Adsorber dan Gelas Ukur dengan

\begin{tabular}{|c|c|c|c|c|c|c|c|c|}
\hline \multirow{2}{*}{ No } & \multirow{2}{*}{ Tanggal } & Pengujian & \multirow{2}{*}{$\begin{array}{c}\text { Temper } \\
\text { atur } \\
\text { rata- } \\
\text { rata } \\
\text { adsorbe } \\
\mathrm{r}^{\circ} \mathrm{C}\end{array}$} & \multirow{2}{*}{$\begin{array}{l}\text { Tekana } \\
\mathrm{n} \text { (Bar) }\end{array}$} & \multicolumn{2}{|c|}{$\begin{array}{c}\text { Volume } \\
\text { refrigeran }\end{array}$} & \multirow{2}{*}{\begin{tabular}{l} 
Efisiensi \\
Adsorbe \\
$\mathrm{r}$ \\
\multicolumn{1}{c}{$\%$}
\end{tabular}} & \multirow{2}{*}{$\begin{array}{c}\text { Efisiensi } \\
\text { Gelas } \\
\text { Ukur } \\
\%\end{array}$} \\
\hline & & $\begin{array}{l}\text { Adsorber } \\
\text { Gelas ukur } \\
\text { Diisolasi }\end{array}$ & & & $\begin{array}{c}\text { Disera } \\
\mathrm{p} \\
(\mathrm{mL})\end{array}$ & $\begin{array}{l}\text { Kemba } \\
\text { li (mL) }\end{array}$ & & \\
\hline \multirow{2}{*}{1} & $\begin{array}{c}20 \\
\text { Februari } \\
2014\end{array}$ & \multirow{2}{*}{$\begin{array}{c}\text { Tidak } \\
\text { Menggunaka } \\
\mathrm{n} \text { mimis } \\
\text { (Metanol) }\end{array}$} & 125,28 & $-0,5333$ & 250 & & \multirow{2}{*}{13,87} & \multirow{2}{*}{30,72} \\
\hline & $\begin{array}{c}21 \\
\text { Februari } \\
2014\end{array}$ & & 26,90 & $-0,7599$ & & 250 & & \\
\hline \multirow{2}{*}{2} & $\begin{array}{c}22 \\
\text { Februari } \\
2014\end{array}$ & \multirow{2}{*}{$\begin{array}{c}\text { Menggunaka } \\
\mathrm{n} \text { mimis } \\
\text { (Metanol) }\end{array}$} & 224,97 & $-0,5333$ & 350 & & \multirow{2}{*}{32,06} & \multirow{2}{*}{43,81} \\
\hline & $\begin{array}{c}23 \\
\text { Februari } \\
2014\end{array}$ & & 30,39 & $-0,8333$ & & 350 & & \\
\hline
\end{tabular}

\section{Refrigeran Metanol.}

Maka dapat disimpulkan bahwa penyerapan metanol yang terbesar adalah adsorber dengan mengunakan mimis, itu disebabkan karena panas yang deserap oleh mimis memiliki penyerapan panas yang lebih besar di bandingkan adsorber yang tidak memakai mimis.

\section{KESIMPULAN DAN SARAN Kesimpulan}

1. Adsorpsi pada pengujian masing-masing refrigeran berlangsung selama 16 jam (mulai jam 17.00 WIB sampai dengan pukul 09.00 WIB pada keesokan harinya). Desorpsi pada pengujian masing-masing refrigeran berlangsung selama 8 jam (mulai pukul 09.00 WIB sampai dengan pukul 17.00 WIB).

2. Hasil/data dari proses adsorpsi:

- Gelas ukur diisolasi dengan styrofoam (dengan menggunakan mimis)

a. Volume refrigeran metanol yang dapat diserap (adsorpsi) sama dengan volume refrigeran metanol yang keluar dari karbon aktif dan alumina aktif dengan menggunakan mimis (proses desorpsi) yaitu sebesar $350 \mathrm{~mL}$.

- Gelas ukur diisolasi dengan styrofoam (tidak menggunakan mimis)

b. Volume refrigeran metanol yang dapat diserap (adsorpsi) sama dengan volume refrigeran metanol yang keluar dari karbon aktif dan alumina aktif tidak menggunakan mimis (proses desorpsi) yaitu sebesar $250 \mathrm{~mL}$.

3. Efisiensi kolektor

a. Efisiensi kolektor dengan menggunakan mimis pada pengujian dengan gelas ukur diisolasi styrofoam adalah sebagai berikut ini.

- Efisiensi kolektor pada pengujian Metanol sebesar: 32,06 \%

b. Efisiensi kolektor tidak menggunakan mimis pada pengujian dengan gelas ukur diisolasi styrofoam adalah sebagai berikut ini.

- Efisiensi kolektor pada pengujian Metanol sebesar: 13,87 \% 
4. Efisiensi Gelas Ukur

a. Efisiensi gelas ukur pada pengujian dengan kondisi diisolasi Styrofoam dengan menggunakan mimis adalah sebagai berikut ini.

- $\quad$ Efisiensi gelas ukur pada pengujian Metanol sebesar: 43,81\%

b. Efisiensi gelas ukur pada pengujian dengan kondisi diisolasi styrofoam tidak menggunakan mimis adalah sebagai berikut ini.

Efisiensi gelas ukur pada pengujian Metanol sebesar: 30,72\%

5. Untuk memaksimalkan penyerapan panas di dalam adsorber maka digunakan benda yang berbahan stainless steel berupa mimis (Stainless steel ball), tetapi dalam menggunakan mimis memiliki kendala yang di dapat yaitu faktor biaya yang terlalu mahal, maka dapat disimpulkan bahwa bahan alternatif untuk mengganti mimis berupa baut,mur,potongan plat,dan lain-lain yang terbuat dari bahan stainless.

\section{Saran}

Saran dari penulis untuk penelitian selanjutnya adalah sebagai berikut.

1. Pengelasan pada alat pengujian harus bagus. Sehingga tidak ada kobocoran.

2. Pengikat kasa nyamuk harus kuat. Sehingga karbon aktif dan alumina aktif tidak keluar dari katup.

3. Untuk proses adsorpsi yang lebih efektif, sebaiknya ditambahkan katup ekspansi untuk menurunkan tekanan.

4. Pada gelas ukur dipilih bahan yang memiliki konduktivitas tinggi dan diusakan permukaannya luas sehingga baik pertukaran panasnya.

5. Menggunakan selang antara adsorben dengan gelas ukur jangan terlalu panjang agar mempermudah proses adsorpsi dan desorpsi dengan baik.

\section{DAFTAR PUSTAKA}

[1] Ambarita, Himsar. 2012. Buku Kuliah teknik Pendingin \& Pengkondisian Udara. Medan

[2] Damanik, Masrin. 2011. Kajian Ekperimental Untuk Mesin Pendingin Siklus Adsorpsi yang Digerakkan Energi Surya. USU

[3] L. W Wang, dkk. The Performance of Two Adsorpstion Ice Making Test Units Using Actived Carbon and a Carbon Composite as Adsorbents. Journal of Applied Thermal Engineering. China.

[4] Sitorus T.B., Napitupulu F.H. \& Ambarita H. 2016. International Journal of Technology, IJTech Journal, Vol. 7 Issue 5, pp. 910-920.

[5] Incropera, F.P., DeWit, Bergan, Lavine. 2006. Fundamentals of Heat and Mass Transfer, $6^{\text {th }}$ edition.

[6] Jhon H. Lienhard. 2006. A Heat Transfer Textbook. Phlogiston Press : Cambridge,Massachusetts,USA 




